\title{
Anti-inflammatory dosing of theophylline in the treatment of status asthmaticus in children
}

\author{
Nemr S Eid' \\ Adrian O'Hagan' \\ Scott Bickel' \\ Ronald Morton' \\ Sarah Jacobson ${ }^{2}$ \\ John A Myers ${ }^{3}$ \\ 'Division of Pediatric Pulmonology, \\ University of Louisville, ${ }^{2}$ Department \\ of Pharmacy, Kosair Children's \\ Hospital, ${ }^{3}$ Department of Pediatrics, \\ University of Louisville, Louisville, \\ KY, USA
}

This article was published in the following Dove Press journal: Journal of Asthma and Allergy

13 October 2016

Number of times this article has been viewed

Background: Low-dose theophylline has been recognized for its ability to restore histone deacetylase-2 activity which leads to improved steroid responsiveness and thus improved clinical outcome. We retrospectively evaluated the effect of low-dose theophylline therapy in pediatric patients hospitalized for an acute asthma exacerbation as a proof of concept study.

Methods: We compared patients who received low-dose theophylline (5-7 mg/kg/day) in addition to current standard of care to patients who were treated with current standard of care alone. The primary outcome of the study was hospital length of stay (LOS). Generalized linear mixed-effects modeling (GLMM) was used to test whether receiving theophylline independently predicted outcomes. A Cox (proportional hazards) regression model was also developed to examine whether theophylline impacted LOS.

Results: After adjustment for illness severity measures, theophylline significantly reduces LOS ( $\beta=-21.17, P<0.001)$, time to discontinue oxygen $(\beta=-15.88, P=0.044)$, time to spirometric improvement $(\beta=-16.60, P=0.014)$, and time to space albuterol $(\beta=-23.2, P<0.001)$ as well as reduced costs ( $\beta=-\mathrm{US} \$ 2,746, P<0.001$ ). Furthermore, theophylline significantly increased the hazards of being discharged from the hospital (hazards ratio $=1.75,95 \%$ confidence interval $1.20-2.54, P=0.004)$. There was no difference in side effects between patients who receive low-dose theophylline and those who did not.

Conclusion: The results of this retrospective study suggest low-dose theophylline may have a positive effect in acute status asthmaticus. This study suggests that further research with a prospective, randomized, double-blinded, placebo controlled trial may be warranted to confirm and extend our findings.

Keywords: theophylline, pediatric asthma, HDAC2, status asthmaticus

\section{Introduction}

Theophylline has been used for over 70 years for its bronchodilation properties in the management of asthma and is widely prescribed throughout the world today. ${ }^{1}$ It is well known for its bronchodilator properties by competitive inhibition of the phosphodiesterase enzyme which results in increased cyclic adenine monophosphate and subsequent smooth muscle relaxation. ${ }^{2}$ To achieve optimal bronchodilation while minimizing side effects, the serum concentrations must be frequently monitored to be maintained within a narrow therapeutic range $(10-20 \mathrm{mg} / \mathrm{mL}){ }^{3}$ When the recommended serum theophylline concentrations are exceeded, side effects can include headaches, dizziness, nervousness, insomnia, nausea, and vomiting. More serious, but rare, side effects include cardiac dysrhythmias and seizures.
Correspondence: Nemr S Eid

Division of Pediatric Pulmonology,

University of Louisville, 57I South

Floyd Street, Suite 4I4, Louisville,

KY 40202, USA

Tel +I 5028523772

Fax + I 502852 405।

Email nseid@louisville.edu 
Theophylline's bronchodilator effects have made it a mainstay of therapy for inpatient asthma management for decades. ${ }^{4}$ Given the potential toxicity and unclear efficacy, the intravenous (IV) formulation of theophylline has fallen out of favor for bronchodilation with the rise of selective beta agonists, and its use is now discouraged by National Asthma Education and Prevention Program (NAEPP) guidelines. ${ }^{5}$ Despite this, published surveys continue to report its use in the pediatric intensive care unit (PICU) for severe refractory patients. ${ }^{6}$ Over the past two decades, there has been increasing interest in the potential role of low-dose oral theophylline ( $5-7 \mathrm{mg} / \mathrm{kg} / \mathrm{dose}$ ) as an adjuvant therapy in the management of asthma for its anti-inflammatory properties. ${ }^{78}$ In this dosing range, side effects are diminished, and there is a less need for chronic monitoring of levels. The most recent iteration of the Global Initiative for Asthma guidelines includes low-dose theophylline as a possible adjunctive outpatient controller therapy, ${ }^{9}$ though the 2007 NAEPP guidelines do not make reference to low-dose theophylline specifically. Neither set of guidelines remark on the use of low-dose theophylline for acute status asthmaticus.

Theophylline, at low plasma concentrations, may act as an immunomodulator by exerting an inhibitory effect of T-lymphocytes in the airway of asthmatic patients, ${ }^{8}$ inducing neutrophil apoptosis, ${ }^{10}$ and suppressing inflammatory gene expression. ${ }^{11}$ In addition, theophylline may prevent downregulation of $\beta$ receptors by $\beta^{2}$ agonists. ${ }^{12}$ One of the most important anti-inflammatory properties of low-dose theophylline is its ability to restore histone deacetylase-2 (HDAC2) activity which leads to improved steroid responsiveness. ${ }^{11,13,14}$

Although theophylline at conventional doses is well studied in acute asthma, there remains a paucity of information on the utility of low-dose theophylline in the management of acute asthma. Several studies have examined its use in chronic asthma management in both adults ${ }^{15-19}$ and children, ${ }^{17,18}$ with positive findings in adults but not in children (though passive smoke exposure was not reported in the pediatric studies). The primary purpose of this study was to retrospectively examine whether provider's addition of low-dose theophylline to standard inpatient asthma therapy appeared to be related to clinical improvement and decreased length of stay (LOS) and costs for pediatric patients hospitalized for status asthmaticus.

\section{Methods}

\section{Study design}

A single-center, retrospective analysis of 273 pediatric patients ( $\geq 5$ years of age), who were hospitalized for $>72$ hours at a pediatric teaching hospital for status asthmaticus, was performed from August 2008 to July 2010. Status asthmaticus was defined as an acute asthma exacerbation with persistent symptoms unresponsive to initial bronchodilator therapy. Patients may have been admitted to the PICU or general wards. The 72-hour time frame was chosen, as it exceeds the mean LOS in pediatric status asthmaticus of 2.4 days and is a surrogate of more severe disease. At our institution (Kosair Children's Hospital, Louisville, KY, USA), the use of low-dose theophylline has been an acceptable modality in treating children with status asthmaticus if they fail to respond to standard inpatient asthma therapy (including systemic corticosteroids, frequent short-acting $\beta_{2}$ agonists, and anticholinergics). The study was approved by the Institutional Review Board of the University of Louisville; the need for patient consent was waived due the retrospective nature of the study. Patients with status asthmaticus as their primary diagnosis were identified using International Classification of Diseases, ninth revision (ICD-9) codes, and their electronic medical records were then evaluated for inclusion in the study.

Patients were excluded from the study if they were taking theophylline as a home medication or were receiving conventional (high) dose theophylline during their hospital admission. Other exclusion criteria included the presence of other chronic lung disease including cystic fibrosis, chronic lung disease of prematurity and sickle cell disease, or microbiological evidence of a concomitant respiratory infection as determined by a sample from sputum, bronchoalveolar lavage (if done), or nasopharyngeal swab. A total of 166 patients met inclusion criteria, and their data were included for analysis. A retrospective, observational study design was used.

Patient demographics were collected, including age, sex, race, LOS, PICU admission, and home asthma medications. The following medications received within 72 hours of admission were recorded: magnesium sulfate (IV bolus or IV drip), ipratropium (scheduled doses or a one-time dose), and systemic corticosteroids (IV or orally [PO]). The use of supplemental oxygen, time to discontinuation of supplemental oxygen, and time to space albuterol to every 4 hours were assessed. If the patient received low-dose theophylline, the dosage form, dose per body weight, number of doses, and time to start theophylline were collected.

\section{Comparison groups}

Patients were included in the low-dose theophylline group if they received theophylline at a dose of $5-7 \mathrm{mg} / \mathrm{kg} /$ day during their hospital admission. The use of low-dose theophylline was not random and was solely a decision of the attending or consulting physician. During the same time period, a majority 
of children with status asthmaticus at our institution did not receive low-dose theophylline. As such, a comparison of the two groups allowed us to investigate if low-dose theophylline was associated with significantly different patient characteristics; in addition, an unadjusted view of clinical outcomes at baseline allowing us, thus, to recognize potential confounders and bias which exist between the two groups, as randomization in the current study was not plausible. Adjustments for traditional risk factors and confounders had to be made due to the nonexperimental (nonrandomness) of the study design. All variables significant in the univariate analysis were incorporated in the generalized linear mixed-effects model (GLMM) and the Cox model (as well as whether the patient received theophylline). This included smoke exposure, inhaled corticosteroids (ICSs), long-acting beta agonist (LABA), and oxygen (Tables 1 and 2).

Patients were managed based on institution asthma guidelines developed from the 2007 NAEPP guidelines ${ }^{5}$ and

Table I Generalized linear mixed-effects models in which the outcomes were made a function of theophylline, smoke exposure, ICS, LABA, and oxygen

\begin{tabular}{|c|c|c|c|}
\hline$\overline{\text { Outcome }}$ & Predictor & B (95\% Cl) & $P$-value \\
\hline \multirow[t]{5}{*}{ LOS (hours) } & Theophylline & $-21.17(-10.1,-32.2)$ & $<0.00 I^{* *}$ \\
\hline & Smoke exposure & $2.50(-7.9,12.7)$ & 0.633 \\
\hline & ICS & $9.22(-21.1,2.6)$ & 0.125 \\
\hline & LABA & $-6.10(-7.2,19.0)$ & 0.380 \\
\hline & Oxygen & $-14.76(-0.9,30.2)$ & 0.063 \\
\hline \multirow{6}{*}{$\begin{array}{l}\text { Time to off } \\
\mathrm{O}_{2} \text { (hours) }\end{array}$} & Theophylline & $-15.88(-0.42,-31.3)$ & $0.044^{* *}$ \\
\hline & & & \\
\hline & Smoke exposure & $0.954(-13.5,15.4)$ & 0.896 \\
\hline & ICS & $|1.7|(-27.8,4.8)$ & 0.155 \\
\hline & LABA & $-12.35(-6.4,31.1)$ & 0.194 \\
\hline & Oxygen & - & - \\
\hline \multirow{6}{*}{$\begin{array}{l}\text { Time to } \\
\text { PFT (hours) }\end{array}$} & Theophylline & $-16.6(-3.4,-29.8)$ & $0.014^{* *}$ \\
\hline & & & \\
\hline & Smoke exposure & $7.55(-4.8,19.9)$ & 0.229 \\
\hline & ICS & $10.84(-25.8,4.2)$ & 0.155 \\
\hline & LABA & $-4.74(-10.8,0.3)$ & 0.547 \\
\hline & Oxygen & $-22.4(-4.7,-40.2)$ & $0.014^{* *}$ \\
\hline \multirow{5}{*}{$\begin{array}{l}\text { Time to } q 4 \mathrm{~h} \\
\text { albuterol } \\
\text { (hours) }\end{array}$} & Theophylline & $-23.2(-11.6,-34.8)$ & $<0.00 I^{* *}$ \\
\hline & Smoke exposure & $7.96(-2.9,18.8)$ & 0.149 \\
\hline & ICS & $7.97(-20.3,4.4)$ & 0.205 \\
\hline & LABA & $-8.78(-5.3,22.9)$ & 0.220 \\
\hline & Oxygen & $-21.23(-5.45,-37.0)$ & $0.009 * *$ \\
\hline \multirow{5}{*}{$\begin{array}{l}\text { Costs } \\
\text { (dollars) }\end{array}$} & Theophylline & $-\$ 2746(-\$ 4 \mathrm{~K},-\$ I \mathrm{~K})$ & $<0.00 I^{* *}$ \\
\hline & Smoke exposure & $\$ 856(-\$ 553, \$ 2 \mathrm{~K})$ & 0.232 \\
\hline & ICS & $\$ 1235(-\$ 3 K, \$ 380)$ & 0.133 \\
\hline & LABA & $-\$ 688(-\$ 1 \mathrm{~K}, \$ 2 \mathrm{~K})$ & 0.452 \\
\hline & Oxygen & $-\$ 424 \mathrm{I}(-\$ 2 \mathrm{~K},-\$ 6 \mathrm{~K})$ & $<0.00 I^{* *}$ \\
\hline
\end{tabular}

Note: $* * P<0.05$.

Abbreviations: ICS, inhaled corticosteroid; LABA, long-acting beta agonist; LOS, length of stay; PFT, pulmonary function testing; $\mathrm{Cl}$, confidence interval; q4h, every 4 hours.
Table 2 Cox regression models in which the timed outcomes were made a function of theophylline, smoke exposure, ICS, LABA, and oxygen

\begin{tabular}{|c|c|c|c|}
\hline Outcome & Predictor & HR (95\% Cl) & $P$-value \\
\hline \multirow[t]{5}{*}{ LOS (hours) } & Theophylline & $1.75(1.20-2.54)$ & $0.004 * *$ \\
\hline & Smoke exposure & $0.97(0.76-I .5 I)$ & 0.690 \\
\hline & ICS & $0.81(0.55-1.20)$ & 0.294 \\
\hline & LABA & $1.16(0.73-1.82)$ & 0.535 \\
\hline & Oxygen & $1.38(0.8 \mathrm{I}-2.33)$ & 0.237 \\
\hline \multirow{6}{*}{$\begin{array}{l}\text { Time to off } \\
\mathrm{O}_{2} \text { (hours) }\end{array}$} & Theophylline & $1.68(1.12-2.54)$ & $0.012^{* *}$ \\
\hline & & & \\
\hline & Smoke exposure & $0.94(0.64-1.36)$ & 0.727 \\
\hline & ICS & $0.68(0.45-1.03)$ & 0.068 \\
\hline & LABA & $1.59(0.97-2.63)$ & 0.064 \\
\hline & Oxygen & - & - \\
\hline \multirow{5}{*}{$\begin{array}{l}\text { Time to PFT } \\
\text { (hours) }\end{array}$} & Theophylline & $2.12(1.34-3.39)$ & $0.00 I^{* *}$ \\
\hline & Smoke exposure & $0.99(0.66-1.48)$ & 0.950 \\
\hline & ICS & $0.72(0.45-1.17)$ & 0.187 \\
\hline & LABA & $1.40(0.82-2.38)$ & 0.216 \\
\hline & Oxygen & $2.63(1.40-4.94)$ & $0.003^{* *}$ \\
\hline \multirow{4}{*}{$\begin{array}{l}\text { Time to q4h } \\
\text { albuterol } \\
\text { (hours) }\end{array}$} & Theophylline & $2.43(1.61-3.39)$ & $<0.00 I^{* *}$ \\
\hline & Smoke exposure & $1.04(0.72-1.50)$ & 0.847 \\
\hline & ICS & $0.74(0.48-1.12)$ & 0.155 \\
\hline & LABA & $1.44(0.87-2.37)$ & 0.158 \\
\hline
\end{tabular}

Note: $* * p<0.05$.

Abbreviations: ICS, inhaled corticosteroid; LABA, long-acting beta agonist; LOS, length of stay; PFT, pulmonary function testing; $\mathrm{HR}$, hazards ratio; $\mathrm{Cl}$, confidence interval; q4h, every 4 hours.

our institutional experience (Figure 1). Patients were given supplemental oxygen to maintain arterial oxygen saturation of $92 \%$ or greater. All patients received inhaled short-acting $\mathrm{b}_{2}$-adrenergic agonists and systemic corticosteroids. The dose, route of administration, timing of these agents, the use of additional therapy, and subspecialist consultation were left to the hospitalist's discretion. Patients with severe status asthmaticus are generally given IV methylprednisolone at a dose of $1 \mathrm{mg} / \mathrm{kg}$ every 6 hours. Therapy is later de-escalated to oral prednisolone at a dose of $1 \mathrm{mg} / \mathrm{kg}$ every 12 hours when the patient is clinically improving. If the attack is not deemed severe from the outset, patients are usually started on oral prednisolone at the dose previously stated. When patients show clinical improvement and are able to tolerate inhaled short-acting $\beta_{2}$-adrenergic agonists every 4 hours, they undergo spirometry to objectively confirm discharge readiness as defined as by a forced expiratory volume in 1 second $\left(\mathrm{FEV}_{1}\right)^{3} 70 \%$ or greater of their personal best or predicted value. ${ }^{5}$

\section{Statistical analysis}

Patients were stratified into receiving theophylline $(\mathrm{n}=57$, $34.5 \%)$ and not receiving theophylline ( $\mathrm{n}=109,65.5 \%)$. Chi-squared tests were used to test for differences in 


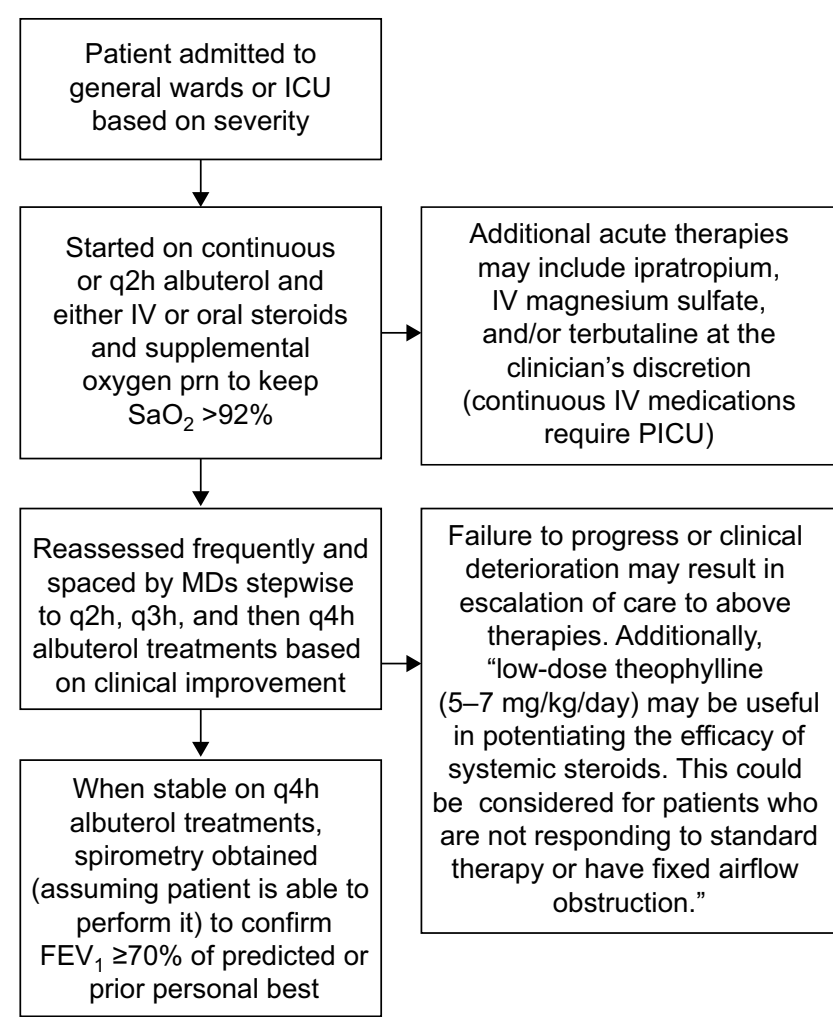

Figure I Summary of treatment algorithm for status asthmaticus at Kosair Children's Hospital.

Notes: The algorithm was developed by institution's (Kosair Children's Hospital) multidisciplinary asthma task force based on 2007 National Asthma Education and Prevention Program (NAEPP) guidelines. Patients on oral steroids were treated with prednisolone at I $\mathrm{mg} / \mathrm{kg} /$ dose BID, while those on IV steroids were treated with methylprednisolone $1 \mathrm{mg} / \mathrm{kg} /$ dose every 6 hours.

Abbreviations: ICU, intensive care unit; q2h, every 2 hours; q3h, every 3 hours; q4h, every 4 hours; IV, intravenous; prn, pro re nata; PICU, pediatric ICU; BID, twice a day; $\mathrm{FEV}_{\mathrm{I}}$, forced expiratory volume in I second; MD, medical doctor.

categorical variables between those who received theophylline and those who did not, while Student's $t$-tests were used to test for differences in continuous variables. GLMM was initially used to test whether receiving theophylline independently predicted 1) LOS, 2) time to wean off oxygen, 3) time to spirometric improvement (time to pulmonary function testing [PFT]), 4) time to spaced (every 4 hours) albuterol treatment, and 5) overall costs. All variables significant in the univariate analysis were incorporated in the GLMM (as well as whether the patient received theophylline). Cox (proportional hazards) regression models were developed to examine whether theophylline impacted the hazard of being discharged from the hospital. This is an interesting example in which an increased hazard (being discharged from the hospital) is a good/desired outcome.

An economic evaluation was performed concurrently with the intervention trial. Initially, we performed a straightforward cost-minimization analysis. That is, we calculated all costs associated with both using theophylline and not using theophylline and indicated which strategy incurs the fewest costs. In addition, as we hypothesized that LOS would be different between the two management strategies, we performed a cost-effectiveness analysis by calculating an incremental cost-effectiveness ratio (ICER). Effectiveness was measured as shorter hospital stay, while all direct costs from our institution were used to define costs. Combined with the within-trial data, an estimate of the ICER according to a traditional decision analytic model was calculated. All costs were in 2010 US dollars (the year the data were collected). The effect of uncertainty in clinical and economic data was assessed by following the techniques outlined in Briggs et al. ${ }^{20}$ For threshold analyses, variables were considered sensitive if the incremental cost per hospital-free day exceeded US\$100,000. Lastly, we forecasted the potential national savings if theophylline was used in patients with more than 3 days of in-hospital admission approximately $25 \%$ of cases.

\section{Results}

Fifty-seven patients were included in the low-dose theophylline group and 109 in the control group. The average dose of theophylline received by patients in the low-dose theophylline group was $5.4 \mathrm{mg} / \mathrm{kg} /$ day; actual body weight was used unless the ideal body weight was smaller. Treatment with theophylline did not begin until an average of 67.1 hours after admission and was continued for a mean of 3.7 days. The most common theophylline preparation used was a 24-hour extended release product (Theo-24; Actient Pharmaceuticals, LLC, Lake Forest, IL, USA). There was no difference in side effects of therapy between the two groups.

Per our protocol, patients on PO steroids were treated with prednisolone at $1 \mathrm{mg} / \mathrm{kg} /$ dose twice a day (BID) while those on IV steroids were treated with methylprednisolone $1 \mathrm{mg} / \mathrm{kg} /$ dose every 6 hours as discussed earlier. In Table 3, we report that $47.4 \%$ of the Theophylline group and $31.2 \%$ of the No Theophylline group were on IV steroids, which was a statistically significant difference $(P=0.04)$ and reflected the fact that the Theophylline group represented a more severe group. Incorporation of this variable in the multivariable models had no impact on parameter estimates. We present the most parsimonious model in which dose of steroid was not included.

In addition to being more likely to receive IV steroids, those who received theophylline during their stay in the hospital were significantly more likely to need supplemental 
Table 3 Patient characteristics and outcomes stratified by receiving theophylline or not receiving theophylline during their stay in the hospital

\begin{tabular}{|c|c|c|c|}
\hline $\begin{array}{l}\text { Categorical } \\
\text { variable }\end{array}$ & $\begin{array}{l}\text { Theophylline } \\
N=57 \text { (\%) }\end{array}$ & $\begin{array}{l}\text { No theophylline } \\
N=109 \text { (\%) }\end{array}$ & $P$-value \\
\hline Male & $32(56.1)$ & $66(60.6)$ & 0.583 \\
\hline Ethnicity & & & 0.273 \\
\hline Black & $35(61.4)$ & $68(62.4)$ & \\
\hline White & $19(33.3)$ & $39(35.8)$ & \\
\hline Other & $3(5.3)$ & $2(1.8)$ & \\
\hline PICU & $27(47.4)$ & $58(53.2)$ & 0.475 \\
\hline Smoking exposure & $31(54.4)$ & $35(32.1)$ & $0.005^{* *}$ \\
\hline History of asthma & $55(96.5)$ & $106(97.3)$ & 0.787 \\
\hline History of atopy & $36(65.5)$ & $51(58.0)$ & $0.37 \mid$ \\
\hline IV steroid & $27(47.4)$ & $34(31.2)$ & $0.040^{* *}$ \\
\hline LTRA & $36(33.1)$ & $27(47.4)$ & 0.071 \\
\hline ICS & $44(76.8)$ & $55(50.5)$ & $0.001 * *$ \\
\hline LABA & $20(35.1)$ & $21(19.3)$ & $0.025^{* *}$ \\
\hline Oxygen & $53(93.0)$ & $88(80.7)$ & $0.036 * *$ \\
\hline Anticholinergics & $\mathrm{I}(\mathrm{I} .8)$ & $0(0.0)$ & 0.167 \\
\hline Magnesium & $45(79.0)$ & $95(87.2)$ & 0.167 \\
\hline $\begin{array}{l}\text { Continuous } \\
\text { variable }\end{array}$ & $\begin{array}{l}\text { Theophylline } \\
\text { Mean (SD) }\end{array}$ & $\begin{array}{l}\text { No theophylline } \\
\text { Mean (SD) }\end{array}$ & $P$-value \\
\hline Age (years) & $10.1(3.2)$ & $10.1(3.4)$ & 0.988 \\
\hline $\mathrm{FEV}_{\text {, }}(\%$ predicted $)$ & $77.6(15.4)$ & $78.3(15.0)$ & 0.820 \\
\hline $\begin{array}{l}\text { FEF } 25-75(\% \\
\text { predicted) }\end{array}$ & $60.0(20.4)$ & $60.0(20.7)$ & 0.991 \\
\hline $\mathrm{FEV}_{1} / \mathrm{FVC}$ ratio & $0.79(0.09)$ & $0.80(0.09)$ & 0.516 \\
\hline TLC (\% predicted) & $100.8(18.0)$ & $96.4(17.8)$ & 0.359 \\
\hline RV (\% predicted) & $167.8(63.2)$ & $159.3(57.9)$ & 0.596 \\
\hline $\mathrm{RV} / \mathrm{TLC}$ ratio & $0.33(0.090$ & $0.34(0.10)$ & 0.955 \\
\hline $\begin{array}{l}\text { Time to off } \mathrm{O}_{2} \\
\text { (hours) }\end{array}$ & $73.2(45.1)$ & $56.5(34.5)$ & $0.014 * *$ \\
\hline $\begin{array}{l}\text { Time to PFT } \\
\text { (hours) }\end{array}$ & $120.9(37.2)$ & $106.8(26.9)$ & $0.023^{* *}$ \\
\hline $\begin{array}{l}\text { Time to albuterol } \\
\text { every } 4 \text { hours } \\
\text { (hours) }\end{array}$ & $123.8(36.0)$ & $102.6(29.2)$ & $<0.00 I^{* *}$ \\
\hline LOS (hours) & $135.6(35.5)$ & $116.2(26.2)$ & $<0.00 I^{* *}$ \\
\hline Costs (dollars) & $\$ 14,325(\$ 5 K)$ & $\$ 12,050(\$ 4 \mathrm{~K})$ & $0.002^{* *}$ \\
\hline
\end{tabular}

Note: **Significant at the 0.05 level.

Abbreviations: ICS, inhaled corticosteroid; LABA, long-acting beta agonist; LOS, length of stay; PFT, pulmonary function testing; IV, intravenous; PICU, pediatric intensive care unit; $\mathrm{FEV}_{1}$, forced expiratory volume in I second; FVC, forced vital capacity; FEF, forced expiratory flow; RV, residual volume; TLC, total lung capacity; LTRA, leukotriene receptor antagonist; SD, standard deviation.

oxygen therapy $(93.0 \%$ vs $80.7 \%, P=0.036)$, to have been on ICS as outpatient ( $76.8 \%$ vs $50.5 \%, P=0.001)$, and been on LABA therapy $(35.1 \%$ vs $19.3 \%, P=0.025)$. They also had more exposure to cigarette smoke $(54.4 \%$ vs $32.1 \%, P=0.005)$ when compared to those who did not receive theophylline. As such, it can be inferred that those who received low-dose theophylline had higher levels of illness severity. Therefore, from an unadjusted perspective, those who received theophylline took significantly longer to be taken off oxygen (73.2 hours vs 56.5 hours, $P=0.014$ ), to have PFT performed
(120.9 hours vs 106.8 hours, $P=0.023$ ), to be spaced on albuterol (123.8 hours vs 102.6 hours, $P<0.001$ ), and to be discharged from the hospital (135.6 hours vs 116.2 hours, $P<0.001)$. Similarly, they had significantly increased costs (US\$14,325 vs US\$12,050, $P=0.002$ ).

However, after adjustment for illness severity measures, as seen in Table 1, theophylline significantly reduces LOS ( $\beta=-21.17, P<0.001)$, time to wean off oxygen $(\beta=-15.88$, $P=0.044)$, time to PFT ( $\beta=-16.60, P=0.014)$, and time to space albuterol $(\beta=-23.2, P<0.001)$; as well as reduced costs $(\beta=-\mathrm{US} \$ 2,746, P<0.001)$. In addition, as seen in Table 1 , receiving oxygen therapy reduced time until PFT performed $(\beta=-22.40, P=0.014)$, and time to space albuterol $(\beta=21.23, P=0.009)$; as well as reduced costs ( $\beta=-\mathrm{US} \$ 4,241, P<0.001)$.

Similar to previously mentioned results, theophylline significantly increased the hazards of being discharged from the hospital (hazards ratio $[\mathrm{HR}]=1.75,95 \%$ confidence interval [CI] 1.20-2.54, $P=0.004)$, time to wean off oxygen $(\mathrm{HR}=1.68,95 \% \mathrm{CI} 1.12-2.54, P=0.012)$, time to spirometric improvement $(\mathrm{HR}=2.12,95 \%$ CI 1.34-3.39, $P=0.001)$, and time to space albuterol (HR $=2.43,95 \%$ CI 1.61-3.39, $P<0.001$ ) (Table 2).

\section{Discussion}

Although the use of conventional doses of theophylline for bronchodilation in acute status asthmaticus is well established, there is currently no literature regarding low-dose theophylline in acute status asthmaticus in either children or adults. Low-dose theophylline has been used in the management of chronic asthma and was recently reviewed elsewhere. ${ }^{7}$ Our study is the first to our knowledge to suggest clinical improvement in a cohort of children with severe status asthmaticus treated with low-dose theophylline as an add-on to usual asthma therapy. After adjustment for illness severity measures, low-dose theophylline significantly reduced LOS and hospital costs. The baseline demographics were similar in both the groups at baseline, but a few distinct differences are noteworthy. First, the low-dose theophylline group consisted of more patients who were on a LABA/ ICS combination therapy at home and were still hypoxemic 72 hours into their illness. Therefore, the low-dose theophylline group may have represented a more severe patient population. Second, the low-dose theophylline group consisted of patients who had greater exposure to second-hand tobacco smoke at home. Our study found that it took on an average of 67.1 hours until the first dose of theophylline was administered. This likely explains the greater LOS in 
those patients who received low-dose theophylline before adjusting for severity of illness. It is possible that the benefit of low-dose theophylline may have been achieved if this therapy was begun earlier.

The pathophysiology behind asthma is complex, has been recently reviewed elsewhere in depth, ${ }^{21,22}$ and is a key in determining pharmacological targets. Ito et $\mathrm{al}^{11}$ and Cosio et $\mathrm{al}^{23}$ described a novel mechanism of action of theophylline, the activation HDAC2 to suppress the inflammatory gene transcription. In the asthmatic airways, inflammatory stimuli cause activation of transcription factors, like nuclear factor- $\kappa \mathrm{B}$, which are responsible for histone acetyltransferase (HAT) activation. HAT acetylates core histones and causes an increase in the inflammatory gene transcription. Corticosteroids act to suppress this inflammation by recruiting HDAC2 to the transcription complex of inflammatory genes and reversing the histone acetylation. At low-serum levels, theophylline activates HDAC2 through inhibition of phosphoinositide-3-kinase delta $(\mathrm{PI} 3 \mathrm{~K} \delta$ ) when it is recruited to the inflammatory site by corticosteroids. Inhibition of $\mathrm{PI} 3 \mathrm{~K} \delta$ has been shown to restore glucocorticoid function in cigarette smoke-exposed mouse models. ${ }^{24}$ This effect is lost at higher concentrations by inhibition of HDAC2 by trichostatin A. ${ }^{25}$ This mechanism is being targeted in patients with COPD who classically have low HDAC2 levels and in patients with severe asthma, ${ }^{13,26-28}$ particularly those with exposure to significant oxidative and nitrative stress such as cigarette smoke. ${ }^{29-31}$

Recent evidence suggests that passive smoke exposure in children with severe asthma results in impairment of HDAC2 activity as in COPD, suggesting this subset of patients may be at particular risk for developing steroid resistance. ${ }^{32}$ Therefore, it is postulated that the addition of low-dose theophylline will exert an anti-asthma effect by increasing activation of HDAC2 which is then recruited by corticosteroids to the site of action to suppress inflammatory genes. It is therefore interesting to note that our theophylline group had greater exposure to passive cigarette smoke, thus a good target for low-dose theophylline treatment.

As with any retrospective review, limitations exist. This is an observational study in which the process governing the exposure to theophylline does not resemble random assignment. As such, it is difficult to definitively attribute all changes in outcomes over time to the exposure to theophylline. Although we discuss and adjust for the numerous (potential and real) confounders, it still raises concerns about whether we empirically defined the attributable protective nature of theophylline (in reducing costs and improving outcomes over time). At best, we can state that there is a strong association between theophylline and improved outcomes over time. However, given that in this retrospective, observational study, clinicians were allowed to manage their patients freely, a truly experimental design was not used, but nonetheless, it is a real-life research. This type of research has been recently applied to improve and set quality standards to understand the optimum role of real-life data in informing meaningful clinical practice guidelines. ${ }^{33}$ Therefore, we believe that this study and its results provide the preliminary evidence to support a prospective study in which exposure to low-dose theophylline is decided by random assignment and not clinician preference.

From an adjusted perspective, based on the economic evaluation, the low-dose theophylline management strategy appears superior to not using theophylline. That is, the theophylline group performed better on both attributes - costs and effectiveness. Those who were prescribed theophylline, from an adjusted perspective, had a shorter hospital stay ( -0.882 days) and incurred fewer costs (-US\$2,746). From an unadjusted perspective, however, the no theophylline group dominated the theophylline group, but this may be an artifact related to the greater illness severity of the theophylline group.

There are an estimated 450,000 admissions for status asthmaticus in the US annually. If only $25 \%$ of hospitalized asthmatics were prescribed theophylline (estimated proportion having LOS >3 days; ie, severe asthmatics), we anticipate that theophylline use could introduce US\$309M in cost-savings nationally and 99,225 hospital-free days gained (data not shown).

\section{Conclusion}

Our study suggests that adding low-dose theophylline to children with status asthmaticus is a safe alternative that may positively affect clinical parameters, shorten hospital stay, and decrease overall health care costs. This study strongly suggests that larger prospective, randomized, double-blinded, placebo-control trials be conducted to confirm and extend our findings.

\section{Acknowledgment}

Data from this paper were presented at the 2015 American Thoracic Society International Conference in Denver, CO, USA.

\section{Disclosure}

The authors report no conflicts of interest in this work. 


\section{References}

1. Cosio BG, Soriano JB. Theophylline again? Reasons for believing. Eur Respir J. 2009;34(1):5-6.

2. Pediatric Lexi-Drugs Online [database on the Internet]. December 28, 2010 ed. Hudson, OH: Lexi-Comp, Inc; 2010

3. American Academy of Pediatrics Committee on Drugs: precautions concerning the use of theophylline. Pediatrics. 1992;89(4 Pt 2):781-783.

4. Wheeler DS, Jacobs BR, Kenreigh CA, Bean JA, Hutson TK, Brilli RJ. Theophylline versus terbutaline in treating critically ill children with status asthmaticus: a prospective, randomized, controlled trial. Pediatr Crit Care Med. 2005;6(2):142-147.

5. National Asthma Education and Prevention Program. Expert Panel Report 3 (EPR-3): Guidelines for the Diagnosis and Management of AsthmaSummary Report 2007. J Allergy Clin Immunol. 2007;120(5 Suppl): S94-S138.

6. Dalabih AR, Bondi SA, Harris ZL, Saville BR, Wang W, Arnold DH. Aminophylline infusion for status asthmaticus in the pediatric critical care unit setting is independently associated with increased length of stay and time for symptom improvement. Pulm Pharmacol Ther. 2014;27(1):57-61.

7. Barnes PJ. Theophylline. Am J Respir Crit Care Med. 2013;188(8): 901-906.

8. Kidney J, Dominguez M, Taylor PM, Rose M, Chung KF, Barnes PJ. Immunomodulation by theophylline in asthma. Demonstration by withdrawal of therapy. Am J Respir Crit Care Med. 1995;151(6):1907-1914.

9. Bousquet J, Humbert M. GINA 2015: the latest iteration of a magnificent journey. Eur Respir J. 2015;46(3) 579-582.

10. Yasui K, Agematsu K, Shinozaki K, et al. Theophylline induces neutrophil apoptosis through adenosine A2A receptor antagonism. J Leukoc Biol. 2000;67(4):529-535.

11. Ito K, Lim S, Caramori G, et al. A molecular mechanism of action of theophylline: induction of histone deacetylase activity to decrease inflammatory gene expression. Proc Natl Acad Sci USA 2002;99(13):8921-8926.

12. Cosio BG, Tsaprouni L, Ito K, Jazrawi E, Adcock IM, Barnes PJ. Theophylline restores histone deacetylase activity and steroid responses in COPD macrophages. J Exp Med. 2004;200(5):689-695.

13. Cosio BG, Iglesias A, Rios A, et al. Low-dose theophylline enhances the anti-inflammatory effects of steroids during exacerbations of COPD. Thorax. 2009;64(5):424-429.

14. To Y, Ito K, Kizawa Y, et al. Targeting phosphoinositide-3-kinasedelta with theophylline reverses corticosteroid insensitivity in chronic obstructive pulmonary disease. Am J Respir Crit Care Med. 2010;182(7): 897-904.

15. Ukena D, Harnest U, Sakalauskas R, et al. Comparison of addition of theophylline to inhaled steroid with doubling of the dose of inhaled steroid in asthma. Eur Respir J. 1997;10(12):2754-2760.

16. Lim S, Jatakanon A, Gordon D, Macdonald C, Chung KF, Barnes PJ. Comparison of high dose inhaled steroids, low dose inhaled steroids plus low dose theophylline, and low dose inhaled steroids alone in chronic asthma in general practice. Thorax. 2000;55(10):837-841.
17. Evans DJ, Taylor DA, Zetterstrom O, Chung KF, O’Connor BJ, Barnes PJ. A comparison of low-dose inhaled budesonide plus theophylline and high-dose inhaled budesonide for moderate asthma. NEngl J Med. 1997; 337(20):1412-1418.

18. Nie H, Zhang G, Liu M, Ding X, Huang Y, Hu S. Efficacy of theophylline plus salmeterol/fluticasone propionate combination therapy in patients with asthma. Respir Med. 2013;107(3):347-354.

19. Spears M, Donnelly I, Jolly L, et al. Effect of low-dose theophylline plus beclometasone on lung function in smokers with asthma: a pilot study. Eur Respir J. 2009;33(5):1010-1017.

20. Briggs AH, Weinstein MC, Fenwick EAL, et al. Model parameter estimation and uncertainty analysis: a report of the ISPOR-SMDM Modeling Good Research Practices Task Force Working Group-6. Med Decis Making. 2012;32(5):722-732.

21. Bonsignore MR, Profita M, Gagliardo R, et al. Advances in asthma pathophysiology: stepping forward from the Maurizio Vignola experience. Eur Respir Rev. 2015;24(135):30-39.

22. Olin JT, Wechsler ME. Asthma: pathogenesis and novel drugs for treatment. BMJ. 2014;349:g5517.

23. Cosio BG, Mann B, Ito K, et al. Histone acetylase and deacetylase activity in alveolar macrophages and blood mononocytes in asthma. Am J Respir Crit Care Med. 2004;170(2):141-147.

24. Marwick JA, Caramori G, Stevenson CS, et al. Inhibition of PI3Kdelta restores glucocorticoid function in smoking-induced airway inflammation in mice. Am J Respir Crit Care Med. 2009;179(7):542-548.

25. Barnes PJ. Theophylline: new perspectives for an old drug. Am J Respir Crit Care Med. 2003;167(6):813-818.

26. Barnes PJ. Histone deacetylase-2 and airway disease. Ther Adv Respir Dis. 2009;3(5):235-243.

27. Barnes PJ. Corticosteroid resistance in patients with asthma and chronic obstructive pulmonary disease. JAllergy Clin Immunol. 2013; 131(3):636-645.

28. Ford PA, Durham AL, Russell RE, Gordon F, Adcock IM, Barnes PJ. Treatment effects of low-dose theophylline combined with an inhaled corticosteroid in COPD. Chest. 2010;137(6):1338-1344.

29. Ito K, Lim S, Caramori G, Chung KF, Barnes PJ, Adcock IM. Cigarette smoking reduces histone deacetylase 2 expression, enhances cytokine expression, and inhibits glucocorticoid actions in alveolar macrophages. FASEB J. 2001;15(6):1110-1112.

30. Marwick JA, Wallis G, Meja K, et al. Oxidative stress modulates theophylline effects on steroid responsiveness. Biochem Biophys Res Commun. 2008;377(3):797-802.

31. Osoata GO, Yamamura S, Ito M, et al. Nitration of distinct tyrosine residues causes inactivation of histone deacetylase 2. Biochem Biophys Res Commun. 2009;384(3):366-371.

32. Kobayashi Y, Bossley C, Gupta A, et al. Passive smoking impairs histone deacetylase-2 in children with severe asthma. Chest. 2014;145(2): 305-312.

33. Roche N, Reddel HK, Agusti A, et al. Integrating real-life studies in the global therapeutic research framework. Lancet Respir Med. 2013; 1(10):e29-e30.
Journal of Asthma and Allergy

\section{Publish your work in this journal}

The Journal of Asthma and Allergy is an international, peer-reviewed open access journal publishing original research, reports, editorials and commentaries on the following topics: Asthma; Pulmonary physiology; Asthma related clinical health; Clinical immunology and the immunological basis of disease; Pharmacological interventions and
Dovepress

new therapies. This journal is included in PubMed. The manuscript management system is completely online and includes a very quick and fair peer-review system, which is all easy to use. Visit http://www. dovepress.com/testimonials.php to read real quotes from published authors. 